\title{
Characteristic Aroma Compounds in Two New Vitis vinifera Cultivars (Table Grapes) and Impact of Vintage and Greenhouse Cultivation
}

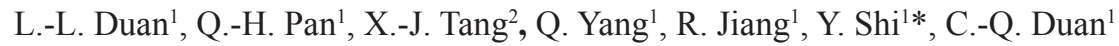

(1) Centre for Viticulture and Oenology, College of Food Science and Nutritional Engineering, China Agricultural University, Beijing 100083, China.

(2) Pomology Institute, Shanxi Academy of Agricultural Sciences, Taigu, Shanxi 030815, China

Submitted for publication: March 2014

Accepted for publication: August 2014

Key words: New hybrids, aroma, greenhouse cultivation, vintage

\begin{abstract}
'Zaoheibao' (a red tetraploid hybrid) and 'Wuhecuibao' (a white triploid hybrid) grapes have been obtained from Guibao $\odot$ (diploid, Vitis vinifera) $\times$ Zaomeigui $\curvearrowright$ (diploid, $V$. vinifera) and Guibao $\bigcirc$ (diploid, $V$. vinifera) $\times$ Wuhebaijixin ${ }^{\lambda}$ (triploid, $V$. vinifera) respectively. Aroma characterisation of the two new table grape cultivars was firstly done by the investigation of volatile compounds. The influence of greenhouse cultivation and vintage on berry aroma was studied as well. The results showed that linalool, decanal, $\beta$-damascenone, hexanal and $(E)$-2-hexenal were the main volatile compounds of the two cultivars, which meant that the floral, fruity and sweet odour were prominent, followed by the herbaceous aroma. Greenhouse cultivation enhanced herbaceous odour in both 'Wuhecuibao' and 'Zaoheibao' berries, and reduced the floral aroma, contributed mainly by $\beta$-damascenone, in 'Wuhecuibao', and the sweet aroma, represented mainly by linalool, in 'Zaoheibao'. The concentrations of the main aroma compounds were greatly affected by vintage and the intensity of sensorial perception was correspondingly changed, but varietal odour attributes were not significantly altered. These results will not only help promote the cultivation and popularisation of these cultivars, but also will provide valuable data for the use of these cultivars in future breeding.
\end{abstract}

\section{INTRODUCTION}

Aroma composition is one of the most important parameters in table grapes and it determines consumers' acceptance to a large extent. Many factors influence the composition and concentration of aroma compounds in grapes, such as cultivar (Garcia et al., 2003), origin (Oliveira et al., 2006), climate (Ristic et al., 2007), degree of maturity (Augustyn \& Rapp, 1982), vineyard management technique (Gonçalves et al., 2008) and vintage (Diéguez et al., 2003). Greenhouse cultivation is one of the staple management techniques around the world, as it can reduce the impact of seasonal climate on fruit production and meet fresh fruit supplement all the year round. In comparison to open field cultivation, greenhouse cultivation generally alters sunlight, $\mathrm{CO}_{2}$ concentration and environmental temperature, which would affect the accumulation of aroma compounds (Schultz, 2000). The effect of vintage on grape aroma compounds is caused similarly by differences in the sum of temperature, sunlight and vine-water balance between different years (Schultz, 2000; Ristic et al., 2007; Mira de Orduña, 2010). Some studies have focused on the influence of greenhouse conditions and vintages on wine grape cultivars (Lafontaine et al., 2004; Des Gachons et al., 2005), but table grapes have received little attention.

Table grapes are mainly used for fresh consumption and make up approximately $90 \%$ of total grape production in China. 'Wuhecuibao' ( $V$. vinifera) and 'Zaoheibao' ( $V$. vinifera) are two new table grape hybrids that were bred by the Shanxi Pomology Institute in China. 'Wuhecuibao' is a triploid hybrid white table grape cultivar from diploid Guibao + ( $V$. vinifera $)$ and triploid Wuhebaijixin ${ }^{\lambda}$ ( $V$. vinifera), while 'Zaoheibao' is a tetraploid hybrid red table grape cultivar from diploid Guibao 9 ( $V$. vinifera) and diploid Zaomeigui ${ }^{\lambda}$ ( $V$. vinifera). 'Wuhecuibao' is an early-ripening, seedless cultivar with a sweet and rich flavour. 'Zaoheibao' has a very large berry $(7.50 \mathrm{~g} /$ berry) with a purple skin, and is crack resistant. Both cultivars have strong resistance against white rot and downy mildew. Until now, these two cultivars have been planted in Shanxi, Gansu, Hebei or other provinces in China, and have been favoured by most consumers due to their good taste and flavour. They have good market prospects. However, aroma

*Corresponding author: Ying Shi, E-mail address: shiy@cau.edu.cn [Tel.: +86-10-62737136; Fax: +86-10-62737136]

Acknowledgements: This research was financially supported by the National Natural Science Foundation of China (Grant No. 31272118 to Q.-H. Pan) 
characterisation of the two Chinese table grape cultivars has not yet been described in detail.

The present study is aimed at illustrating their volatile characteristics and understanding the effects of vintage and greenhouse cultivation on their aroma compounds. This work will help optimise the cultivation of these new cultivars in order to achieve the best flavour quality and provide valuable data for new breeding programmes related to the two hybrids.

\section{MATERIALS AND METHODS \\ Sampling}

Grape berries of 'Zaoheibao' and 'Wuhecuibao'were sampled from the greenhouses and vineyards located at Shanxi Academy of Agricultural Sciences, Shanxi province, China (latitude $112^{\circ} 32^{\prime}$, longitude $37^{\circ} 23^{\prime}$ ) in three growing seasons (2009, 2011 and 2012). 'Zaoheibao' and 'Wuhecuibao' were planted in both greenhouses and open fields in 1996 and 2005 respectively. The rows were orientated in a NorthSouth direction, with a spacing of about 1.5 to $1.8 \mathrm{~m}$ between vines. Berries were taken randomly from both sides of the rows. Grapevines, either 'Zaoheibao' or 'Wuhecuibao', were divided into three biological sampling units, and each unit comprised 10 vines. The samples from different units were placed in different polyethylene bags.

\section{Greenhouse and open field cultivation conditions}

For greenhouse cultivation, vines were planted with a spacing of $1.4 \mathrm{~m}$ in the row and $1.8 \mathrm{~m}$ between rows in three similarly sized polyethylene (PE) $(100 \mu \mathrm{m}$ thick, UVexcluded and IR-filtered) greenhouses $(3.2 \mathrm{~m}$ height, $9 \mathrm{~m}$ width and $68 \mathrm{~m}$ length). The trunks of all grapevines were trained along wires, with the cordon extending horizontally. The two cultivars were also growing in vineyards without any shielding. Cultivation practices for both greenhouse and open field vines were similar regarding fertilisation, irrigation, pruning and disease control. The canopies were trimmed before véraison to maintain a medium-to-high vigour. A proper leaf/fruit ratio $\left(\mathrm{cm}^{2} / \mathrm{g}\right)$ was required in order to balance photosynthetic capacity and carbohydrate accumulation in the grapevines, and the different grape cultivars were generally given different leaf/fruit ratio so as to optimise fruit quality. In this study, leaf/fruit ratio was measured at grape harvest. The ratio was controlled in the range from 25:1 to 30:1 for 'Wuhecuibao', with a grape production of about $15 \times 1000 \mathrm{~kg} / \mathrm{hm}^{2}$, while it ranged from $30: 1$ to $35: 1$ for 'Zaoheibao', with about $25 \times 1000 \mathrm{~kg} / \mathrm{hm}^{2}$ grape production.

For each replicate, approximately 150 berries were selected at random from various directions of 10 grapevines. The berries were sampled at harvest and immediately transported on ice to the laboratory. The grape berries from greenhouse cultivation were collected only in 2009, while grape berries were sampled in the vineyards at the same locations in 2009, 2011 and 2012. About 30 berries for each replicate were used to measure total soluble solids $\left({ }^{\circ}\right.$ Brix, TSS) and total titratable acidity (TTA). The remaining berries were frozen in liquid nitrogen and stored at $-80^{\circ} \mathrm{C}$ prior to analysis.
Sample preparation and extraction of volatile compounds Samples were prepared according to Hellin et al. (2010), with minor modifications. Berries were deseeded, ground into powder and blended under liquid nitrogen. Fifty grams of ground berries was added with $0.5 \mathrm{~g}$ of $D$-glyconicacidlactone (Sigma) and blended to inhibit grape $\beta$-glycosidase activity. After being macerated for $4 \mathrm{~h}$ at $4^{\circ} \mathrm{C}$, the maceration extract was immediately centrifuged at $2000 \mathrm{~g}$ and $4^{\circ} \mathrm{C}$ for $10 \mathrm{~min}$, and clear grape juice was obtained.

Volatile compounds were extracted according to the method reported by Zhang et al. (2007). Five millilitres of the juice, $1.00 \mathrm{~g}$ of $\mathrm{NaCl}$ and $10 \mu \mathrm{l}$ of internal standard 4-methyl-2-pentanol (1 $000 \mathrm{mg} / \mathrm{L})$ were blended in a $15 \mathrm{ml}$ sample vial tightly capped with a PTFE silicon septum and containing a magnetic stirrer. Afterwards ,the vial containing the sample was heated at $40^{\circ} \mathrm{C}$ for $30 \mathrm{~min}$ on a heating platform with $80 \mathrm{rpm}$ agitation. The pretreated (conditioned at $270^{\circ} \mathrm{C}$ for $\left.1 \mathrm{~h}\right) \mathrm{SPME}$ fibre $(50 / 30 \mu \mathrm{m}$ DVB/Carboxen/ PDMS, Supelco, Bellefonte, PA) was then inserted into the headspace. The fibre was subsequently desorbed in the GC injector for $8 \mathrm{~min}$.

\section{GC-MS analysis}

An Agilent 7890 GC equipped with an Agilent $5975 \mathrm{MS}$ and fitted with a $60 \mathrm{~m} \times 0.25 \mathrm{~mm}$ id HP-INNOWAX capillary column with $0.25 \mu \mathrm{m}$ film thickness (J \& W Scientific, Folsom, CA) was employed to separate and identify the aromatic volatiles. Helium was used as the carrier gas at $1 \mathrm{ml} / \mathrm{min}$, and the GC inlet was set in the splitless mode. The starting temperature of the oven was $50^{\circ} \mathrm{C}$, which was held for $1 \mathrm{~min}$, then it was raised to $220^{\circ} \mathrm{C}$ at a rate of $3^{\circ} \mathrm{C} / \mathrm{min}$ and held at $220^{\circ} \mathrm{C}$ for $5 \mathrm{~min}$. The mass spectrometer in the electron impact mode (MS/EI) at $70 \mathrm{eV}$ was scanned in the full scan and selective ion mode (SIM) under autotune conditions at the same time. The area of each peak was determined by ChemStation software (Agilent Technologies).

\section{Quantification}

The quantification procedure was based on prior studies, with modifications (Howard et al., 2005; Jetti et al., 2007). According to the average concentration of sugar and acids in grape juice, a synthetic matrix was prepared in distilled water containing glucose $(200 \mathrm{~g} / \mathrm{L})$ and malic acid $(6 \mathrm{~g} / \mathrm{L})$, and the $\mathrm{pH}$ value was adjusted to 3.5 with $5 \mathrm{~N} \mathrm{NaOH}$ solution. All aroma compound standards were dissolved with ethanol, and then combined together as a single standard solution. This mixed standard solution was diluted into seven levels in succession (fourfold dilution was conducted between two adjacent mixed standard solutions) with the synthetic matrix. Volatile standards of each level were extracted and analysed under the same conditions as the grape samples. For quantifications, calibration curves were obtained, with their regression coefficients all above 97\% (see supplementary material). In addition, volatile compounds without calibration curves were estimated with those standards that had the same functional group and/or similar numbers of carbon atoms.

\section{Odour activity value}

To better illustrate the aroma characteristics of the grape berries, the odour activity value $(\mathrm{OAV})$ was calculated by 
SUPPLEMENTARY MATERIAL

Regression equations for some major volatile compounds in grape berries

\begin{tabular}{|c|c|c|c|}
\hline Standards & Calibration curves $^{a}$ & $\mathrm{r}^{2 b}$ & Linear range $(\mu \mathrm{g} / \mathrm{L})$ \\
\hline hexanal & $y=7.0275 x-0.4848$ & 0.99 & $5.77-23637.6$ \\
\hline$\beta$-myrcene & $y=0.2723 x-0.0024$ & 0.979 & $0.21-851.2$ \\
\hline (E)-2-hexenal & $y=7.6349 x-0.8204$ & 0.989 & $7.98-32692.8$ \\
\hline ethyl hexanoate & $y=0.1494 x+0.0032$ & 0.99 & $0.03-126.17$ \\
\hline octanal & $y=4.9859 x+0.0046$ & 0.981 & $0.05-192.04$ \\
\hline 1-hexanol & $y=1.31 \times-0.04$ & 0.987 & $0.48-1967.13$ \\
\hline (E)-3-hexen-1-ol & $y=5.2956 x+0.0006$ & 0.982 & $0.06-234.22$ \\
\hline (Z)-3-hexen-1-ol & $y=9.7995 x-0.022$ & 0.998 & $1.26-5164.6$ \\
\hline (E)-2-hexen-1-ol & $y=2.9211 x-0.0538$ & 0.998 & $1.5-6124.8$ \\
\hline 2-octanol & $y=0.0982 x+0.0023$ & 0.996 & $0.03-121.77$ \\
\hline ethyl octanoate & $y=0.1502 x+0.0054$ & 0.989 & $0.06-233.23$ \\
\hline 1-octen-3-ol & $y=0.0966 x+0.0004$ & 0.994 & $0.01-40.77$ \\
\hline 2-ethyl-1-hexanol & $y=0.0947 x+0.0008$ & 0.994 & $0.01-43.38$ \\
\hline decanal & $y=3.4735 x+0.0247$ & 0.979 & $0.16-654.39$ \\
\hline linalool & $y=0.4641 x+0.041$ & 0.995 & $0.45-1852.8$ \\
\hline 1-octanol & $y=2.0172 x+0.004$ & 0.995 & $0.06-228.85$ \\
\hline$\alpha$-terpineol & $y=0.3522 x+0.0068$ & 0.99 & $0.06-226.8$ \\
\hline geranyl acetate & $y=0.1507 x+0.0168$ & 0.983 & $0.05-198$ \\
\hline citronellol & $y=0.3058 x+0.0071$ & 0.993 & $0.05-191.9$ \\
\hline methyl salicylate & $y=0.14 x+0.0063$ & 0.989 & $0.05-195.03$ \\
\hline nerol & $\mathrm{y}=0.3865 \mathrm{x}+0.112$ & 0.982 & $0.55-2269.8$ \\
\hline geraniol & $y=0.4864 x+0.1673$ & 0.978 & $0.61-2495.46$ \\
\hline hexanoic acid & $y=1.9137 x+0.1212$ & 0.985 & $0.84-3445.2$ \\
\hline geranylacetone & $y=0.0132 x+0.0046$ & 0.978 & $0.02-68.25$ \\
\hline 2,6-di-tert-butyl-4-methylphenol & $y=0.104 x-0.0012$ & 0.983 & $0.02-79.6$ \\
\hline 2-phenylethanol & $y=3.5392 x+0.1564$ & 0.988 & $1.23-5021.28$ \\
\hline phenol & $y=1.7599 x+0.0018$ & 0.992 & $0.02-101.5$ \\
\hline
\end{tabular}

$a$ : $\mathrm{x}$, peak area ratio of a compound to internal standard; $\mathrm{y}$, concentration in $\mu \mathrm{g} / \mathrm{L} . b: \mathrm{r}^{2}$, regression coefficient

dividing the concentration of a compound by its odour thresholds (OT, determined from the grape matrix), which were obtained from the literature cited in Table 3.

\section{Macroclimatic data}

The macroclimatic data (rainfall, mean temperature, growing degree days and sunshine duration) were provided by the China Meteorological Data Sharing Service System (http://cdc.cma.gov.cn/home.do).

\section{Statistical analysis}

Analysis of variance (ANOVA) or the T-test was used to evaluate differences in the concentrations of each aromatic compound in the grape berries. A significant difference was noted when $\mathrm{P}<0.05$. Hierarchical cluster analysis was performed on the basis of the concentrations of all volatile compounds by adopting Ward's method. Principal component analysis (PCA) was conducted to visualise different berry samples and to establish the relationship between sample and characteristic aroma compounds with OAV over 1. SPSS Statistical Package for Windows version 19.0 (SPSS Inc., USA) was used for all statistical analyses.

\section{RESULTS AND DISCUSSION}

Vintages and cultivation conditions (greenhouse versus vineyard) apparently affected total soluble solids (TSS) in the 'Wuhecuibao' and 'Zaoheibao' berries, while both of them had little influence on total titratable acidity (TTA). TSS was the lowest in the 'Wuhecuibao' grapes in 2012. For the 'Zaoheibao', grapes the lowest TSS was present in 2011 (ANOVA, $\mathrm{P}<0.05$, Table 1). The grapes growing in greenhouses contained less TSS in comparison with those from the open-air vineyards (T-test, $\mathrm{P}<0.05$, Table 1 ).

The types and concentrations of volatile compounds detected by GC-MS from the two grape cultivars are listed in Table 2. In this study, a total of 83 volatile compounds were detected, of which 23 volatiles were present in all 'Wuhecuibao' samples and 21 volatiles in all 'Zaoheibao' samples, regardless of planting location and vintage. These compounds mainly included terpenoids, $\mathrm{C}_{6}$-aldehydes and alcohols. 
TABLE 1

Total soluble solids (TSS) and total titratable acidity (TTA) of 'Wuhecuibao' and 'Zaoheibao' table grape berries

\begin{tabular}{|c|c|c|c|c|}
\hline Grape cultivars & Vintage & Planting location & $\mathrm{TSS} \mathrm{Brix}^{\mathrm{o}}$ & TTA $(\mathrm{g} / \mathrm{L})$ \\
\hline \multirow{4}{*}{ 'Wuhecuibao' } & 2009 & Greenhouse & $16.83 \pm 0.07^{c}$ & $4.65 \pm 0.21^{a}$ \\
\hline & 2009 & Vineyard & $17.03 \pm 0.02^{a b}$ & $4.60 \pm 0.17^{a}$ \\
\hline & 2011 & Vineyard & $17.09 \pm 0.02^{a}$ & $4.70 \pm 0.14^{a}$ \\
\hline & 2012 & Vineyard & $17.00 \pm 0.04^{b}$ & $4.63 \pm 0.22^{a}$ \\
\hline \multirow{4}{*}{ 'Zaoheibao' } & 2009 & Greenhouse & $17.92 \pm 0.04^{c}$ & $4.28 \pm 0.24^{a}$ \\
\hline & 2009 & Vineyard & $18.19 \pm 0.03^{a}$ & $4.31 \pm 0.31^{a}$ \\
\hline & 2011 & Vineyard & $18.05 \pm 0.06^{b}$ & $4.28 \pm 0.19^{a}$ \\
\hline & 2012 & Vineyard & $18.20 \pm 0.02^{a}$ & $4.28 \pm 0.11^{a}$ \\
\hline
\end{tabular}

For a cultivar, different letters in the same column indicate that the values have significant difference $(\mathrm{P}<0.05)$.

\section{Odour profile of 'Wuhecuibao' and 'Zaoheibao' grape berries}

To estimate the contribution of a component to the global aroma of the berries, we adopted OAVs. $\beta$-Damascenone, decanal and linalool presented very high OAVs in both cultivars, meaning that these compounds are predominant contributors of fruit aroma. By combining the OAVs of a group of volatiles with similar odour descriptions (Table 3), an aromatic set could be defined. In the present study, five aromatic sets of volatile compounds were established, namely fruity, floral, sweet, herbaceous and chemical. Floral aroma was the most predominant in these two cultivars, followed by fruity aroma. The berries also showed a slightly sweet and herbaceous aroma, but presented little chemical flavour (Fig. 1).

For 'Wuhecuibao', a total of 76 volatile compounds were identified in the berries, of which 23 compounds were always present in all the samples of this cultivar in this study (Table 2). Based on the 23 compounds, seven odour-active volatiles with OAVs higher than 1 were identified, namely linalool, decanal, $\beta$-damascenone, hexanal, $(E)$-2-hexenal, nonanal and (Z)-3-hexen-1-ol (Table 3). Of the seven odour-active volatiles, linalool, decanal, $\beta$-damascenone, hexanal and (E)-2-hexenal had relatively high OAVs and were thus considered to be characteristic aroma compounds of 'Wuhecuibao' grapes. Floral aroma was prominent, as a result of high OAVs of linalool, decanal and $\beta$-damascenone, which were all described as floral aroma (Fig. 1A, Table 3). Meanwhile, linalool and decanal were also considered as the major contributors of fruity and/or sweet odour. The green herbaceous attribute was mainly due to the contribution of hexanal (OAV > 121) and (E)-2-hexenal (OAV > 94). Low chemical odour was characterised by methyl salicylate. In addition, cis-rose oxide and herbaceous $(E, E)$-2,4-hexadienal with floral attributes had OAVs close to or over 1 in these 'Wuhecuibao' berries. In general, floral, fruity and sweet were the main odour characteristics of the 'Wuhecuibao' berries, followed by herbaceous characteristics.

Of 78 aroma compounds identified in 'Zaoheibao', 21 were detected in all berry samples (Table 2). Of these commonly contained compounds, nine were odour-active volatiles with OAVs over 1, namely linalool, decanal, $\beta$-damascenone, hexanal, (E)-2-hexenal, nonanal, $\beta$-myrcene, (Z)-3-hexen-1-ol and cis-rose oxide (Table 3). Of these nine compounds, $\beta$-damascenone had the highest OAV and greatly contributed to the floral aroma of 'Zaoheibao' berries (Fig. 1B). Fruity and sweet odour characteristics were also obvious for the 'Zaoheibao' grape berries owing to relatively high OAVs of linalool and decanal. OAVs of hexanal and (E)-2-hexenal were above 83 and 63 individually in all the samples of this cultivar, so herbaceous characteristics were important as well. In addition, the concentrations of floral geraniol and citronellol, and the concentration of $(E, E)-2,4-$ hexadienal with green odour, were over or close to their OT in this grape cultivar. Therefore, flowery, fruity and sweet were the main odours of 'Zaoheibao' berries, followed by herbaceous flavour, which is similar to the aroma profile of 'Wuhecuibao'.

Volatile compounds contributing greatly to the aroma of the two new cultivars are linalool, decanal, $\beta$-damascenone, hexanal and $(E)$-2-hexenal. This may be because the cultivars were obtained from Guibao ( $V$. vinifera $L$.) as the female parent, which has a muscat flavour. Guibao ( $V$. vinifera $L$.) was derived from the hybrid of Ispissar $(V$. vinifera $C v$.) and Muskat Vira ( $V$. vinifera $\mathrm{Cv}$.). Muscat grape cultivars are generally rich in terpenoids, green aldehydes and alcohols (Marais, 1983; Bureau et al., 2000; Yang et al., 2011). These similar genetic backgrounds determine the similar odour attributes of the two hybrids studied here. The floral, fruity and sweet odour profile was prominent due to high levels of monoterpenes. Grape cultivars are classified into three groups based on monoterpene concentration: intensely muscat-flavoured cultivars, with a concentration of free monoterpenes up to $6 \mathrm{mg} / \mathrm{L}$, non-muscat but aromatic cultivars, with between 1 and $4 \mathrm{mg} / \mathrm{L}$ free monoterpene, and neutral cultivars, which do not depend upon monoterpenes for their flavour (Mateo \& Jiménez, 2000). Accordingly, 'Wuhecuibao', with an average free monoterpene concentration of $4.63 \mathrm{mg} / \mathrm{L}$, and 'Zaoheibao', with an average free monoterpene concentration of $1.96 \mathrm{mg} / \mathrm{L}$, should belong to non-muscat aromatic varieties. 


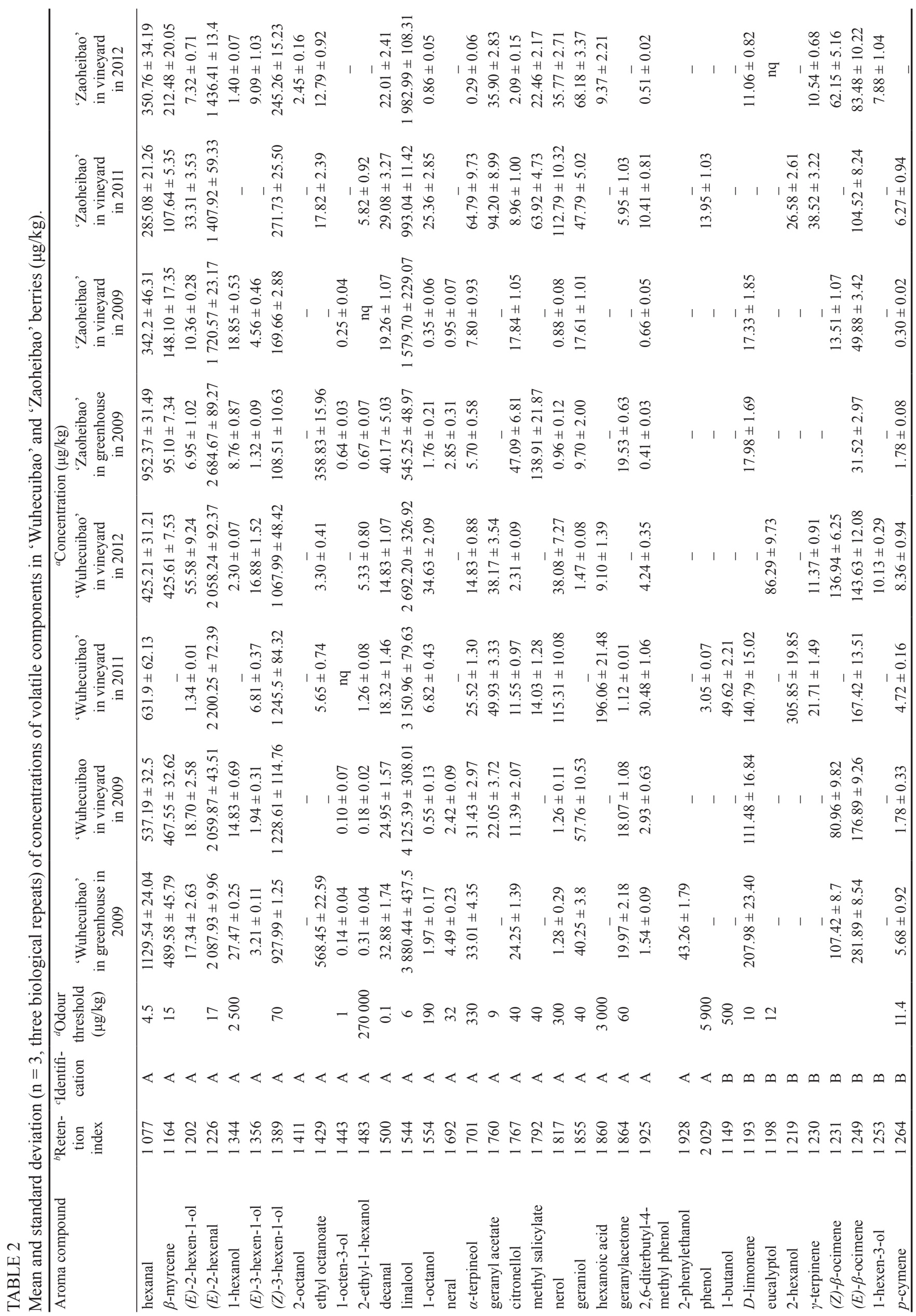




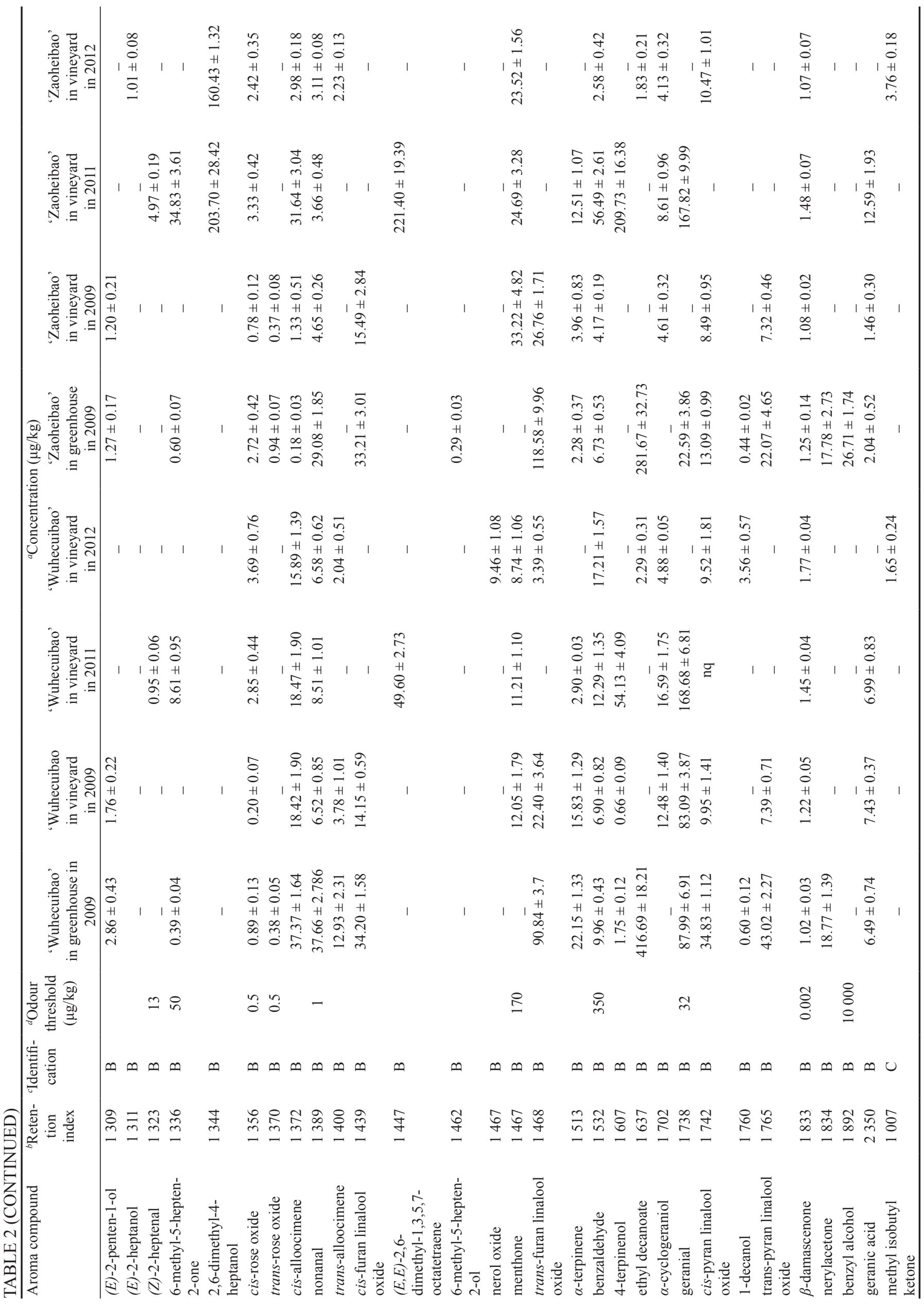




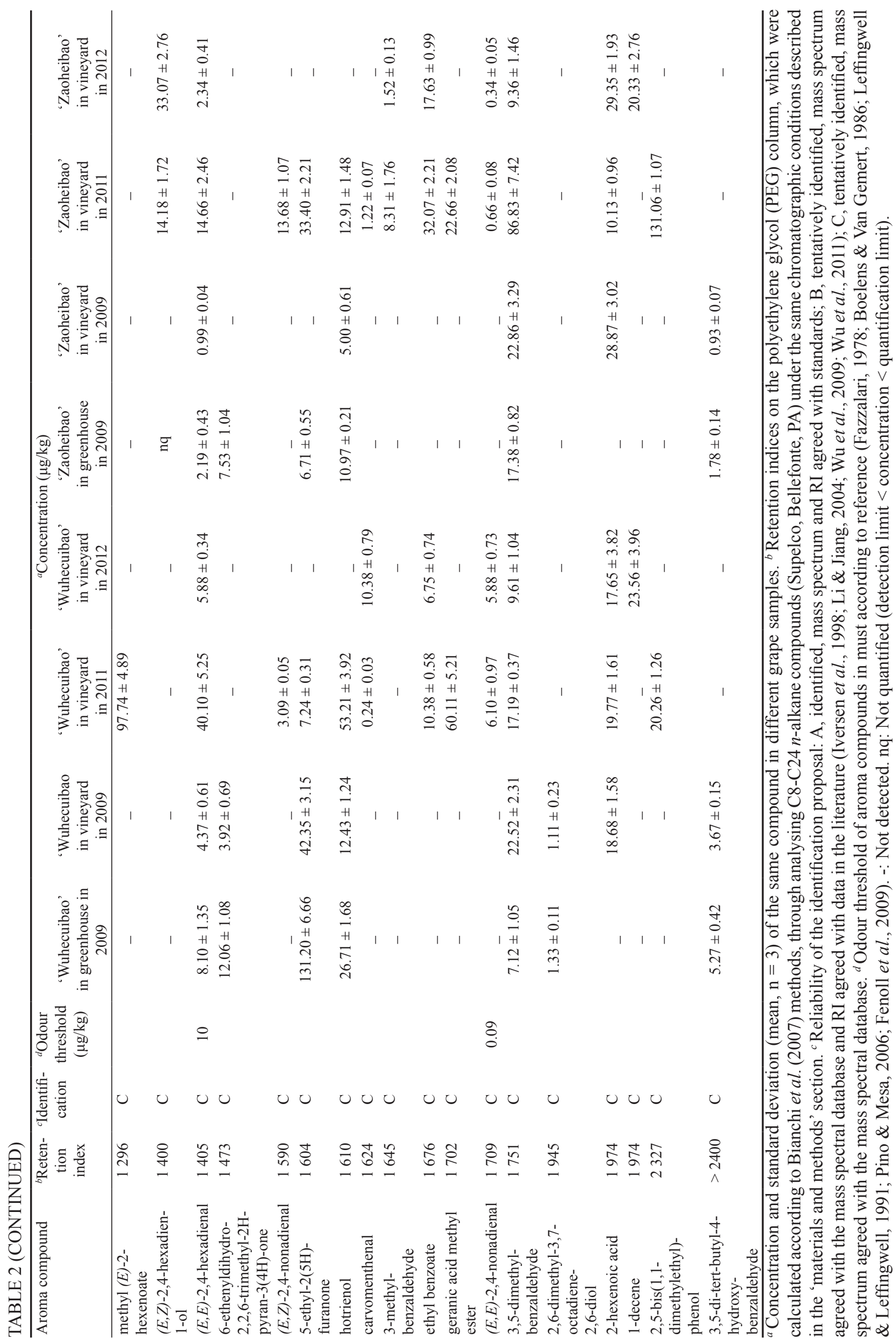



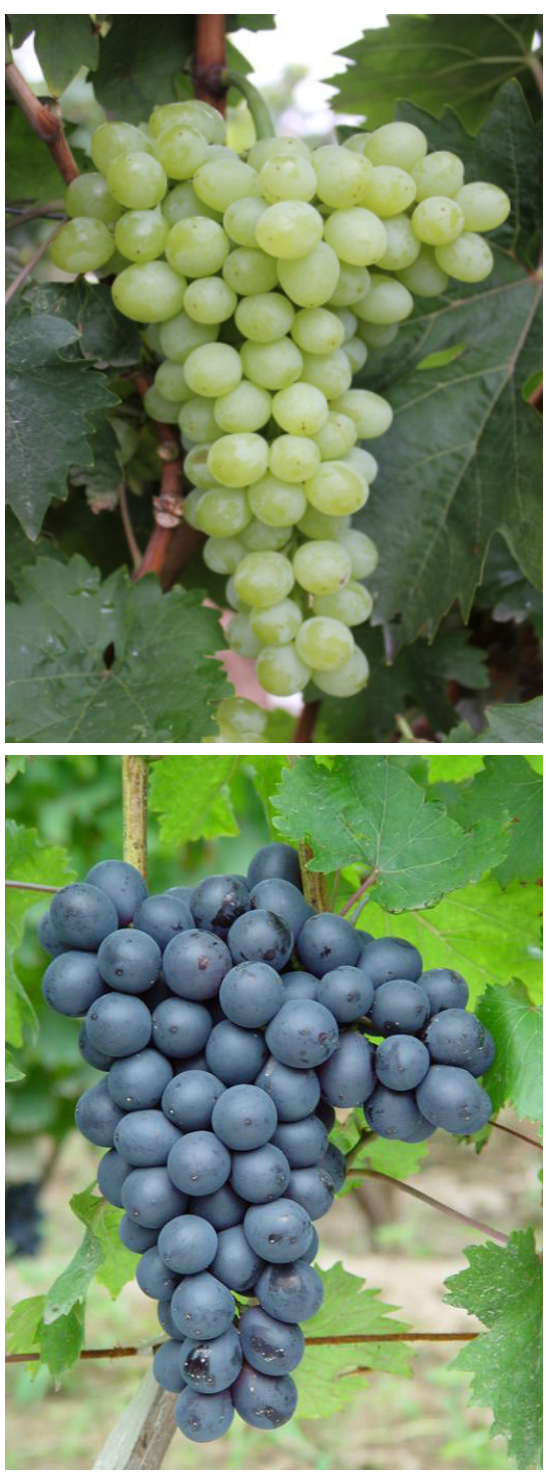

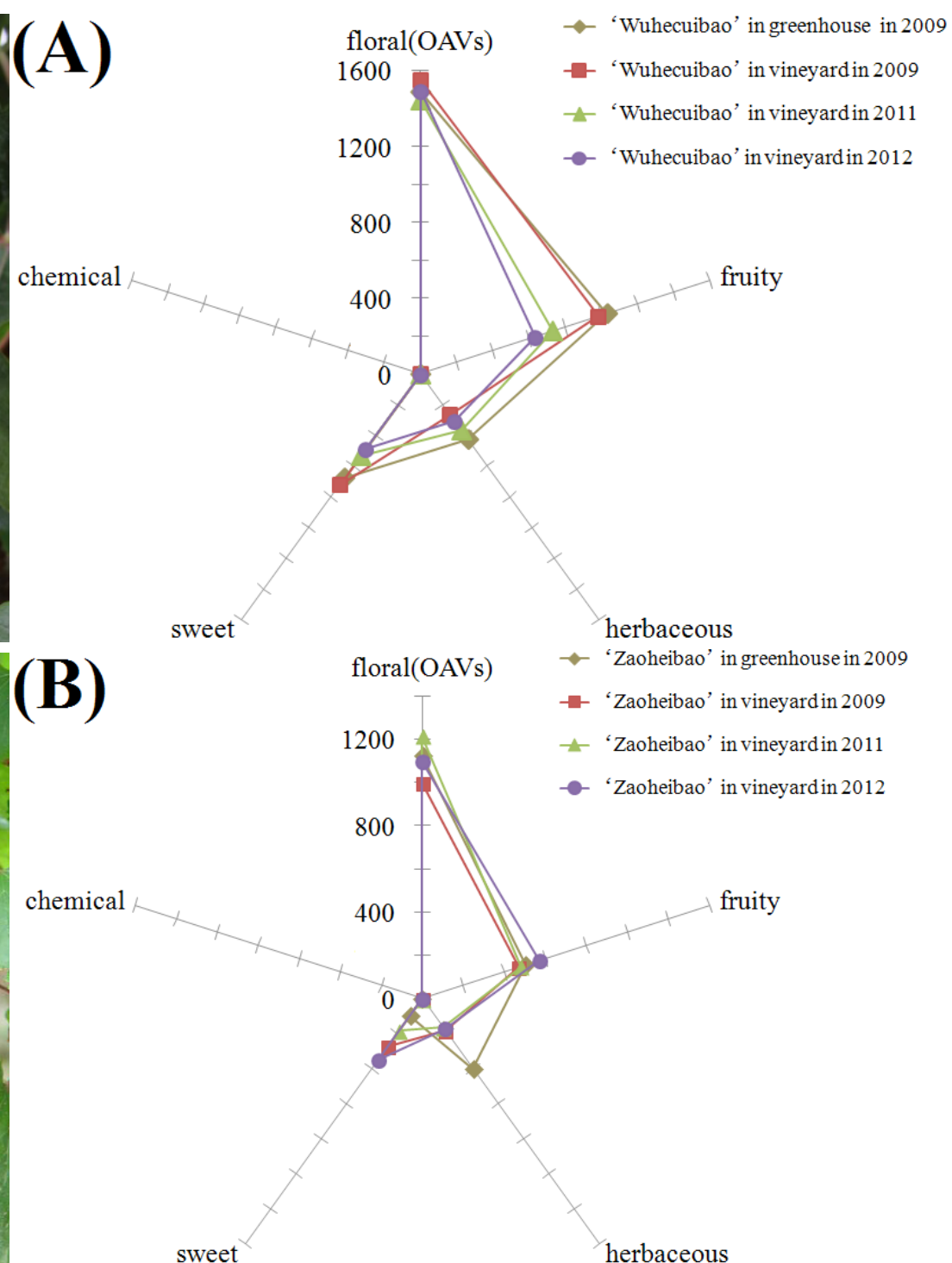

FIGURE 1

Aromatic series in mature 'Wuhecuibao' and 'Zaoheibao'. Aroma compounds calculated for the floral series were: $\beta$-damascenone, linalool, decanal, cis-rose oxide, geraniol, geranyl acetate, trans-rose oxide and citronellol; for the fruity series: linalool, decanal, $\beta$-myrcene, $D$-limonene, geranial, geranyl acetate, citronellol and eucalyptol; for the herbaceous series: $(E)$ 2-hexenal, hexanal, nonanal, (Z)-3-hexen-1-ol, $(E, E)$-2,4-nonadienal and (E,E)-2,4-hexadienal; for the sweet series: linalool, $\beta$-myrcene, geranyl acetate and eucalyptol; for the chemical series: methyl salicylate.

\section{Comparison of aroma compounds between grapes growing in greenhouse and vineyard}

Differences in the composition and concentration of volatiles between grape berries were examined. For both the 'Wuhecuibao' or 'Zaoheibao' cultivar, the greenhouse grape berries contained more abundant and a higher level of total concentration of volatile compounds than these from the vineyard.

In 'Wuhecuibao', 52 volatile compounds were detected in berries collected from the greenhouse, while 49 compounds were detected in the berries from the vineyards. Of all the identified compounds, 45 volatile compounds were present in both the greenhouse and open fields; seven volatiles were found only in the greenhouse fruit (6-methyl5-hepten-2-one, trans-rose oxide, ethyl octanoate, ethyl decanoate, 1-decanol, nerylacetone and 2-phenylethanol) and four compounds (menthone, $\alpha$-cyclogeraniol, geranyl acetate and 2-hexenoic acid) were detected only in the vineyard samples. However, these 11 volatile compounds make little contribution to 'Wuhecuibao' aroma. Volatile compounds with OAV above 1 differed between cultivation environments (greenhouse versus vineyard), which resulted in some difference in fruit aroma attributes.

Compared with the berries collected from the vineyard, the greenhouse 'Wuhecuibao' berries showed significantly higher OAVs of decanal, hexanal, nonanal and $D$-limonene, and lower OAVs of $\beta$-damascenone and (Z)-3-hexen-1-ol (T-test, $\mathrm{P}<0.05$, Fig. 2A). The concentration of cis-rose oxide exceeded its OT only in greenhouse samples, while the concentration of geranyl acetate was higher than its OT only in the vineyard samples (Fig. 2A). The OAVs of hexanal and nonanal in the greenhouse samples were 1.1-fold and 

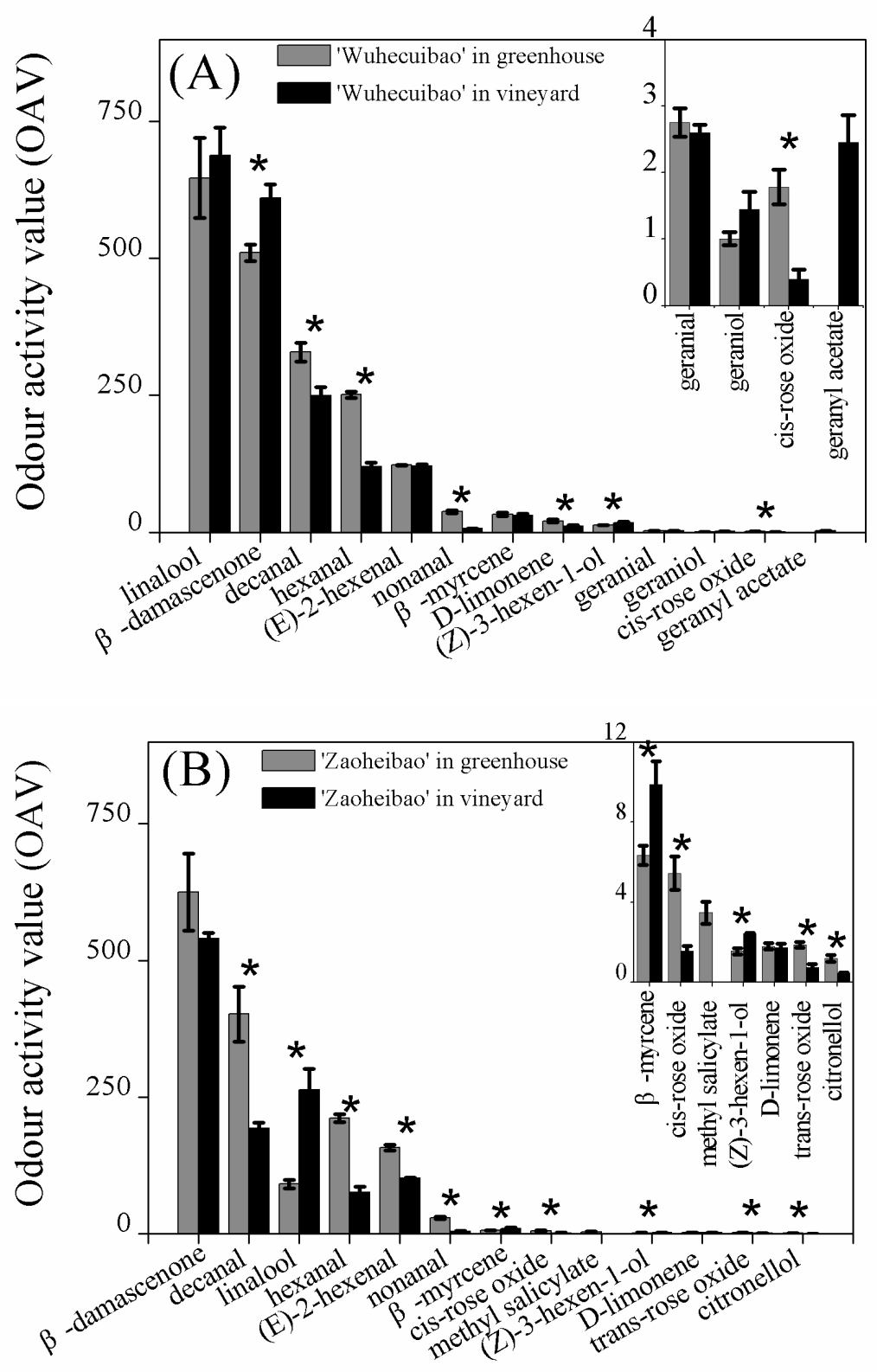

FIGURE 2

Volatile compounds with OAVs $>1$ in 'Wuhecuibao'(A) and 'Zaoheibao' (B) berries growing in the greenhouse and the vineyard. A t-test $(\mathrm{P}<0.05)$ was carried out to compare the impact of cultivation, and the asterisks indicate significant differences between greenhouse and vineyard samples.

4.78-fold higher than those in vineyard samples respectively, which could lead to stronger green or vegetable odours of grape berries grown in the greenhouse. Although the OAV of decanal with floral and fruity aroma in the greenhouse berries was significantly higher than that in the berries grown in the vineyard, the berries from the vineyard still exhibited richer floral aroma characteristics (Fig. 2A). This could be attributed to the relatively higher OAV of $\beta$-damascenone, plus the OAV of geranyl acetate in the vineyard samples. In general, the greenhouse 'Wuhecuibao' berries exhibited more herbaceous characteristics and less floral characteristics when compared with the vineyard berries.

Similarly, more volatile compounds were detected in the greenhouse-grown 'Zaoheibao' berries (51) than in the vineyard berries (42). Thirty-eight compounds were present in both the greenhouse and vineyard samples. Thirteen volatile compounds were found only in the greenhouse berries, namely 6-methyl-5-hepten-2-one, (E,Z)-2,4-hexadien1-ol, ethyl octanoate, 6-methyl-5-hepten-2-ol, 6-ethenyldihydro2,2,6-trimethyl-2H-pyran-3(4H)-one, 5-ethyl-2(5H)furanone, ethyl decanoate, geranial, 1-decanol, methyl salicylate, nerylacetone, geranylacetone, and benzyl alcohol. Four compounds were present only in the vineyard samples, and these were $(Z)$ - $\beta$-ocimene, menthone, $\alpha$-cyclogeraniol and 2-hexenoic acid.

As showed in Figure 2B, there were 10 compounds with OAVs over 1 in the 'Zaoheibao' berries grown in the two environments. Compared with the berries growing in the vineyard, the greenhouse samples were characterised by higher OAVs of decanal, hexanal, $(E)$-2-hexenal, nonanal and cis-rose oxide, as well as lower OAVs of linalool, $\beta$-myrcene and (Z)-3-hexen-1-ol (T-test, $\mathrm{P}<0.05$, Fig. 2B). 
The concentrations of trans-rose oxide, citronellol and methyl salicylate exceeded their odour thresholds $(\mathrm{OAV} \geq 1)$ only in the greenhouse samples (Fig. 2B).

Hexanal, $(E)$-2-hexenal and nonanal were more abundant in the greenhouse samples, which endowed the greenhouse 'Zaoheibao' berries with a richer herbaceous odour (see Fig. 1B). Although (Z)-3-hexen-1-ol, representing a 'green' flavour, was more abundant in the vineyard samples, its OAV was too low to influence overall aroma characteristics. Decanal and linalool are the main aroma compounds in these two cultivars, and they contribute to floral and fruity odour. The vineyard-grown berries had a higher level of linalool and a lower level of decanal in comparison to greenhouse samples, which results in no significant difference between the floral and fruity series. As linalool was also described as a sweet odour compound, the OAV of which, in the vineyard-grown 'Zaoheibao' berries, was 2.90 times of that in greenhouse samples, vineyard 'Zaoheibao' berries exhibited obvious sweet characteristics.

Under greenhouse cultivation, the concentration of $\mathrm{CO}_{2}$ increases and average global surface temperature rises, which leads to the enhancement of evaporation (Gonçalves et al., 2008). Greenhouse cultivation increased the level of total volatiles, especially $\mathrm{C}_{6}$ compounds representing herbaceous flavour, in the 'Wuhecuibao' and 'Zaoheibao' berries. However, Gonçalves et al. (2008) found that most alcohols and aldehydes representing herbaceous flavour were not significantly changed when $\mathrm{CO}_{2}$ concentration increased. On the other hand, Deluc et al. (2009) proved that water deficit in grapevines could increase the transcript abundance of lipoxygenase and hydroperoxidelyase in fatty metabolism and promote the production of $\mathrm{C}_{6}, \mathrm{C}_{9}$ aldehydes and alcohols. Accordingly, it is suggested that higher evaporation in the greenhouse may lead to lower water content in the grapevines, and finally increase herbaceous aroma production. More sunlight exposure was found to increase the levels of norisoprenoids and monoterpenoids (Schultz, 2000; Mira de Orduña, 2010). In contrast, an extremely shaded environment would inhibit the production of $\beta$-damascenone, one of the main norisoprenoids in grape berries (Ristic et al., 2007). Linalool appeared to be very sensitive to sunlight, and the concentration of this volatile compound decreased in response to reduce sunlight (Belancic et al., 1997). Accordingly, the decrease in $\beta$-damascenone in 'Wuhecuibao' and linalool in 'Zaoheibao' grown in the greenhouse suggest we should provide additional

TABLE 3

Odour activity values (OAVs) of main volatile compounds in 'Wuhecuibao' and 'Zaoheibao' berries.

\begin{tabular}{|c|c|c|c|c|}
\hline \multirow[b]{2}{*}{ Aroma compounds } & \multirow[b]{2}{*}{ Odour description } & \multirow[b]{2}{*}{ Aromatic series } & \multicolumn{2}{|c|}{ Odour activity values (OAVs) } \\
\hline & & & 'Wuhecuibao' & 'Zaoheibao' \\
\hline$\beta$-damascenone & floral, lilac ${ }^{a}$ & floral & $510-885$ & $535-740$ \\
\hline linalool & rose, floral, fruity, sweet ${ }^{a, d, e, h}$ & floral, fruity, sweet & $448.7-687.57$ & $90.88-330.5$ \\
\hline decanal & floral, citrus $^{b, e}$ & floral, fruity & $148.3-328.8$ & $192.6-401.7$ \\
\hline (E)-2-hexenal & green $^{c, f}$ & herbaceous & $121.07-129.43$ & $82.82-157.92$ \\
\hline hexanal & green $^{c, f}$ & herbaceous & $94.49-251.01$ & $63.35-211.64$ \\
\hline nonanal & vegetable, green ${ }^{d, f}$ & herbaceous & $6.52-37.66$ & $3.11-29.08$ \\
\hline (Z)-3-hexen-1-ol & green $^{d f f}$ & herbaceous & $13.26-17.79$ & $1.55-3.88$ \\
\hline$(E, E)$-2,4-nonadienal & green $^{d, f}$ & herbaceous & $0-67.78$ & $0-7.33$ \\
\hline$\beta$-myrcene & grape, peach, sweet ${ }^{d, g}$ & fruity, sweet & $0-32.64$ & $6.34-14.17$ \\
\hline$D$-limonene & citrus-like $^{b}$ & fruity & $0-20.8 \pm 2.34$ & $0-1.8$ \\
\hline$c i s$-rose oxide & floral $^{d}$ & floral & $0.4-7.38$ & $1.56-6.66$ \\
\hline geranial & citrus-like, pungent $^{b}$ & fruity & $0-5.27$ & $0-5.24$ \\
\hline geraniol & rose, floral $^{a}$ & floral & $0-1.44$ & $0.24-1.7$ \\
\hline$(E, E)$-2,4-hexadienal & green $^{d}$ & herbaceous & $0.44-4.01$ & $0.1-1.47$ \\
\hline geranyl acetate & fruity, rose, sweet ${ }^{d}$ & fruity, floral, sweet & $0-5.55$ & $0-10.47$ \\
\hline trans-rose oxide & floral $^{d}$ & floral & $<1$ & $0-1.88$ \\
\hline citronellol & lemon, $\operatorname{clove}^{d, h}$ & fruity, floral & $<1$ & $0.05-1.18$ \\
\hline methyl salicylate & butter, alliaceous ${ }^{d}$ & chemical & $<1$ & $0-3.47$ \\
\hline eucalyptol & citrus, sweet $^{d}$ & fruity, sweet & $0-7.19$ & $<1$ \\
\hline
\end{tabular}

Odour description superscript: ${ }^{a}$ reference Selli et al. (2006); ${ }^{b}$ reference Schieberle and Grosch (1988); ${ }^{c}$ reference Darriet et al. (2002); ${ }^{d}$ from Sigma-Aldrich flavour and fragrances catalogue; ${ }^{e}$ reference Chaves et al. (2007); ${ }^{f}$ reference Hashizume and Samuta (1997); ${ }^{g}$ reference Osorio et al. (2006); ${ }^{h}$ reference Ferreira et al. (2001). -: Not detected. nq: Not quantified (detection limit $<$ concentration $<$ quantification limit). 
illumination to avoid the reduction of floral and fruity aroma when the two new cultivars are cultivated in greenhouses.

\section{Influence of vintage on aroma of 'Wuhecuibao' and 'Zaoheibao' berries}

As regards the influence of vintage on the aroma compounds of the two new hybrids, the samples from open-field cultivation were analysed. Vintage affected the composition of volatiles and some compounds. As for 'Wuhecuibao', seven volatile compounds were present only in the 2009 samples, 11 compounds only in the 2011 samples, and seven compounds only in the 2012 samples. Of all the above compounds, only eucalyptol showed an OAV over 1 in 2012 (Table 2). This means that the overall aroma attributes of 'Wuhecuibao' grape berries are hardly affected by vintage, although there is new component production.
Among the compounds that mainly contributed to the aroma of "Wuhecuibao", apart from (E)-2-hexenal, four other compounds, namely linalool, decanal, $\beta$-damascenone and hexanal, showed difference in OAVs between vintages (ANOVA, $\mathrm{P}<0.05$, Fig. 3A). The component that was affected most significantly by vintage was $\beta$-damascenone, which was highest in the 2012 samples. The concentrations of linalool and decanal were highest in the 2009 samples, and the concentration of hexanal was highest in 2011. It is suggested that the perceived intensity of their corresponding aroma in the 'Wuhecuibao' berries would be changed by vintage.

Similar results were also obtained in the 'Zaoheibao' berries. Eight volatile compounds were detected only in the 2009 samples, 13 compounds only in the 2011 samples, and nine compounds only in the 2012 samples. Of these
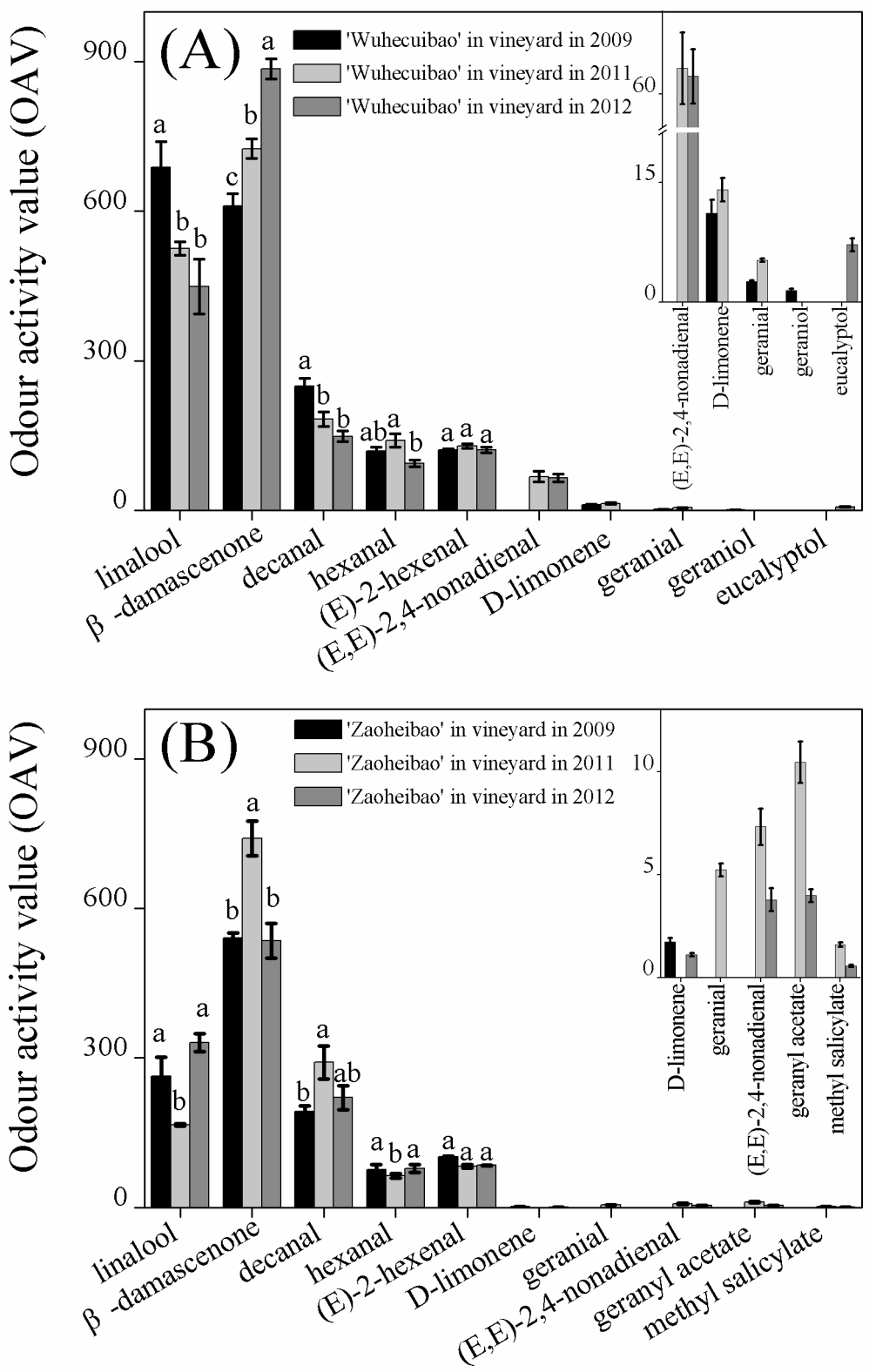

FIGURE 3

The effect of vintage on the main contributory aroma compounds of 'Wuhecuibao' (A) and 'Zaoheibao' (B) berries. ANOVA $(\mathrm{P}<0.05)$ was carried out to compare the impact of vintage, and the letters $\mathrm{a}, \mathrm{b}$ and $\mathrm{c}$ are used to indicate significant differences between the samples from the different years. 
compounds, only geranial showed OAVs over 1 in 2011 (Table 2).

Of the compounds that determined the aroma of the 'Zaoheibao' berries, both linalool and $\beta$-damascenone showed great differences in concentration in different years. Amongst the berries from the three vintages, the 2011 samples contained the lowest OAV of linalool and the highest OAV of $\beta$-damascenone (ANOVA, $\mathrm{P}<0.05$, Fig. 3B). Linalool and $\beta$-damascenone still had relatively high OAVs and both of them represented the floral and fruity aroma. Overall aroma attributes of 'Zaoheibao' seemed to be less changed for vintage, although the intensity of sensorial perception was affected.

In the present study it was found that vintage mainly seemed to influence the relative ratio of monoterpene and $\mathrm{C}_{13}$-norisoprenoid synthesis, both in the 'Wuhecuibao' and 'Zaoheibao' berries. Monoterpene were generated from geranyl diphosphate (GPP), while norisoprenoids were generated from the carotenoid cleavage pathways (Mateo \& Jiménez, 2000; Mendes-Pinto, 2009). For example,

TABLE 4

Temperature and precipitation parameters for the 'Wuhecuibao' and 'Zaoheibao' growing season (June) and ripening period (July).

\begin{tabular}{|c|c|c|c|c|c|c|c|c|}
\hline \multirow[b]{2}{*}{ Period } & \multicolumn{2}{|c|}{ Rain (mm) } & \multicolumn{2}{|c|}{ Mean temperature $\left({ }^{\circ} \mathrm{C}\right)$} & \multicolumn{2}{|c|}{$\begin{array}{c}\text { Growing degree } \\
\text { days }\left({ }^{\circ} \mathrm{C}, \geq 10^{\circ} \mathrm{C}\right)\end{array}$} & \multicolumn{2}{|c|}{ Sunshine duration (h) } \\
\hline & June & July & June & July & June & July & June & July \\
\hline 2009 & 7.7 & 101.9 & 24.0 & 25.0 & 433.2 & 450.1 & 323.3 & 203.2 \\
\hline 2011 & 41.4 & 116.9 & 23.2 & 24.0 & 409.2 & 420.7 & 260.5 & 243.1 \\
\hline 2012 & 44.5 & 118.4 & 22.7 & 24.0 & 394.3 & 421.1 & 292.3 & 214.5 \\
\hline
\end{tabular}
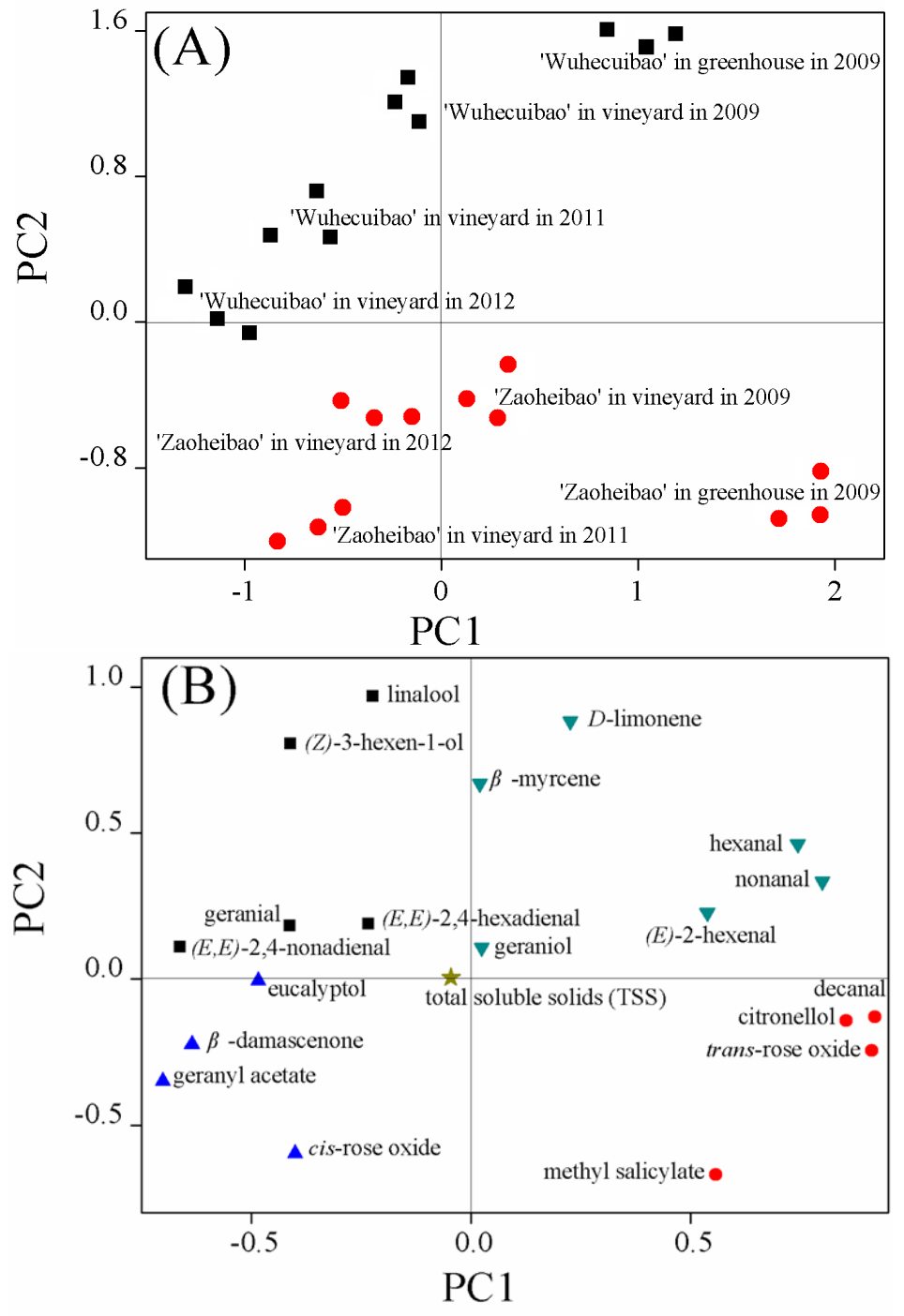

FIGURE 4

Principal component analysis of main aroma compounds (OAV > 1) and total soluble solids (TSS) in 'Wuhecuibao' and 'Zaoheibao' grape berries: (A) scores for the two cultivar fruits; (B) loading for the first two principle components. 
the increase in $\beta$-damascenone from the norisoprenoid pathway was paralleled by the decrease in linalool from the monoterpene pathway in different years for both the 'Wuhecuibao' and 'Zaoheibao' grape berries. Even though both types of compounds are associated with floral and fruity odours, the aroma attributes did not change significantly by vintage for "Wuhecuibao" and "Zaoheibao". In the present study, the vintage impact on grape aroma compounds may be caused mainly by differences in the rainfall, accumulative temperature of the growing season and sunshine hours. Less rainfall was observed in 2009, corresponding to higher average temperatures and more growing degree days in this year. The vintage 2009 had the longest sunshine duration, followed by 2012 and 2011. But, as for the maturity period of the berries, the longest sunshine duration appeared in July of 2011 (Table 4). Previous researchers have shown that sunlight exposure, irrigation and temperature could alter the level of $\mathrm{C}_{13}$-norisoprenoid and/or monoterpenes differently. Higher temperatures (Hornsey, 2007) and long-time sunshine exposure (Schultz, 2000; Mira de Orduña, 2010) can promote linalool production, while lack of irrigation (Song et al., 2012) can reduce the level of $\beta$-damascenone. In this study, the grape-growing period of 2009 presented less rainfall, longer sunshine duration and higher temperatures in comparison to the other two years, which explains the higher concentration of linalool and lower concentration of $\beta$-damascenone in the 'Wuhecuibao' and 'Zaoheibao' grapes growing in vineyards in 2009 (ANOVA, $\mathrm{P}<0.05$, Fig. 3A and 3B). The impact of vintage on the production of volatile compounds should be a combined result of various climate factors. It is difficult at present to evaluate which climate parameter plays a more important role in this process. Interestingly, the synthesis branches of monoterpene and $\mathrm{C}_{13}$-norisoprenoid responded differently to the changing environment over the different vintages, which will be studied further in the future.

\section{PCA analysis}

Considering the differences in TSS and the main contribution of aroma compounds between the two cultivars, PCA was adopted to evaluate the influences of cultivar, location and vintage on TSS and aroma compounds, using TSS (Table 1) and OAV data of the 19 compounds (Table 3) as variables. The first two principal components (PCs) explained 63.1\% of the total variance (PC1 for 35.4\% and PC2 for 27.7\%). Figure 4A shows the scores (projections of the samples onto the PC1 and PC2) in a scatter plot of all samples. Except for 'Zaoheibao' in the vineyard in 2009, the other five vineyard samples of the two cultivars ('Zaoheibao' and 'Wuhecuibao') all presented negative PC1 scores, while all greenhouse samples exhibited positive PC1 scores. The 'Zaoheibao' sample from the vineyard in 2009 showed relatively low positive PC1 scores $(<0.3)$ and it can be clearly separated from all the greenhouse samples with high PC1 scores $(>0.8)$. As a result we thought that PC1 could be used to separate greenhouse grapes from vineyard grapes (Fig. 4A). In addition, nearly all of the 'Wuhecuibao' samples had positive PC2 scores, while all of the 'Zaoheibao' samples had negative PC2 scores. Therefore, PC2 can be used to distinguish the 'Wuhecuibao' cultivar from the 'Zaoheibao' cultivar (Fig. 4A). The findings indicate that each grape cultivar possesses its characteristic aroma profile and that, for a cultivar, vintage has less of an impact than cultivation location. Figure 4B shows the loading plot of main contributing aroma compounds and TSS to PC1 and PC2, which reveals the correspondence between aroma compounds/TSS and grape samples. TSS appears to have a weak association with these grape samples due to its low loading value in both PC1 and PC2 (Fig. 4B). PC1 had the highly positive correlation with nonanal, hexanal, $(E)$ 2-hexenal, decanal, trans-rose oxide, citroellol and methyl salicylate, and was negatively correlated with geranyl acetate, (E,E)-2,4-nonadienal, geranial, eucalyptol, $\beta$-damascenone, (Z)-3-hexen-1-ol and cis-rose oxide (Fig. 4B). Among the above odour compounds, hexanal, (E)-2-hexenal, decanal and $\beta$-damascenone showed great differences in concentration between the vineyard and greenhouse grapes. PC2 correlated positively with linalool, $D$-limonene, (Z)3-hexen-1-ol and $\beta$-myrcene, and negatively with cis-rose oxide and methyl salicylate (Fig. 4B). The relatively high concentration of linalool in the 'Wuhecuibao' grapes is the main characteristic compound distinguishing this cultivar from 'Zaoheibao'.

Although greenhouse cultivation showed enhanced herbaceous odour for both the 'Wuhecuibao' and 'Zaoheibao' cultivars, and while vintage affected floral, fruity and sweet odour to some extent, PCA in this study proved that their influence was limited. The two cultivars have their own characteristic odour profiles. The present results help define the aroma descriptors of the two new cultivars.

\section{CONCLUSIONS}

The aroma compounds of the two new hybrids, 'Wuhecuibao' and 'Zaoheibao', were identified. They are non-muscat aromatic varieties and are rich in floral, fruit and sweet odour compounds. Although greenhouse cultivation and vintage affected the aroma compounds of the two cultivars, their own characteristic odour profiles were not changed greatly.

\section{LITERATURE CITED}

Augustyn, O. \& Rapp, A., 1982. Aroma components of Vitis vinifera L. cv. Chenin blanc grapes and their changes during maturation. S. Afr. J. Enol. Vitic. 3, 47-51.

Belancic, A., Agosin, E., Ibacache, A., Bordeu, E., Baumes, R., Razungles, A. \& Bayonove, C., 1997. Influence of sun exposure on the aromatic composition of Chilean Muscat grape cultivars Moscatel de Alejandria and Moscatel rosada. Am. J. Enol. Vitic. 48, 181-186.

Bianchi, F., Careri, M., Mangia, A. \& Musci, M., 2007. Retention indices in the analysis of food aroma volatile compounds in temperature-programmed gas chromatography: Database creation and evaluation of precision and robustness. J. Sep. Sci. 30, 563-572.

Boelens, M. \& Van Gemert, L., 1986. Physicochemical parameters related to organoleptic properties of flavour components. In: Birch, G.G. \& Lindley, M.G. (eds). Developments in food flavours. London. pp. 23-49.

Bureau, S.M., Razungles, A.J. \& Baumes, R.L., 2000. The aroma of Muscat of Frontignan grapes: Effect of the light environment of vine or bunch on volatiles and glycoconjugates. J. Sci. Food Agric. 80, 2012-2020.

Chaves, M., Zea, L., Moyano, L. \& Medina, M., 2007. Changes in color and odorant compounds during oxidative aging of Pedro Ximenez sweet wines. J. Agric. Food Chem. 55, 3592-3598. 
Darriet, P., Pons, M., Henry, R., Dumont, O., Findeling, V., Cartolaro, P., Calonnec, A. \& Dubourdieu, D., 2002. Impact odorants contributing to the fungus type aroma from grape berries contaminated by powdery mildew (Uncinula necator); Incidence of enzymatic activities of the yeast Saccharomyces cerevisiae. J. Agric. Food Chem. 50, 3277-3282.

Deluc, L.G., Quilici, D.R., Decendit, A., Grimplet, J., Wheatley, M.D., Schlauch, K.A., Mérillon, J.-M., Cushman, J.C. \& Cramer, G.R., 2009. Water deficit alters differentially metabolic pathways affecting important flavor and quality traits in grape berries of Cabernet Sauvignon and Chardonnay. BMC Genomics 10, 212.

Des Gachons, C.P., Leeuwen, C.V., Tominaga, T., Soyer, J.P., Gaudillère, J.P. \& Dubourdieu, D., 2005. Influence of water and nitrogen deficit on fruit ripening and aroma potential of Vitis vinifera L cv Sauvignon blanc in field conditions. J. Sci. Food Agric. 85, 73-85.

Diéguez, S.C., Lois, L.C., Gómez, E.F. \& De la Peña, M.L.G., 2003. Aromatic composition of the Vitis vinifera grape Albariño. L.W.T.-Food Sci. Technol. 36, 585-590.

Fazzalari, F., 1978. Compilation of odor and taste threshold values data. ASTM data series.

Fenoll, J., Manso, A., Hellín, P., Ruiz, L. \& Flores, P., 2009. Changes in the aromatic composition of the Vitis vinifera grape Muscat Hamburg during ripening. Food Chem. 114, 420-428.

Ferreira, V., Aznar, M., Lopez, R. \& Cacho, J., 2001. Quantitative gas chromatography-olfactometry carried out at different dilutions of an extract. Key differences in the odor profiles of four high-quality Spanish aged red wines. J. Agric. Food Chem. 49, 4818-4824.

Garcia, E., Chacón, J., Martínez, J. \& Izquierdo, P., 2003. Changes in volatile compounds during ripening in grapes of Airén, Macabeo and Chardonnay white varieties grown in La Mancha region (Spain). Food Sci. Technol. Int. 9, 33-41.

Gonçalves, B., Falco, V., Moutinho-Pereira, J., Bacelar, E., Peixoto, F. \& Correia, C., 2008. Effects of elevated $\mathrm{CO}_{2}$ on grapevine (Vitis vinifera L.): Volatile composition, phenolic content, and in vitro antioxidant activity of red wine. J. Agric. Food Chem. 57, 265-273.

Hashizume, K. \& Samuta, T., 1997. Green odorants of grape cluster stem and their ability to cause a wine stemmy flavor. J. Agric. Food Chem. 45, 1333-1337.

Hellin, P., Manso, A., Flores, P. \& Fenoll, J., 2010. Evolution of aroma and phenolic compounds during ripening of 'superior seedless' grapes. J. Agric. Food Chem. 58, 6334-6340.

Hornsey, I., 2007. The chemistry and biology of winemaking [Chapter 2]. The Royal Society of Chemistry, Cambridge, UK.

Howard, K.L., Mike, J.H. \& Riesen, R., 2005. Validation of a solid-phase microextraction method for headspace analysis of wine aroma components. Am. J. Enol. Vitic. 56, 37-45.

Iversen, C.K., Jakobsen, H.B. \& Olsen, C.-E., 1998. Aroma changes during black currant (Ribes nigrum L.) nectar processing. J. Agric. Food Chem. 46, 1132-1136.

Jetti, R., Yang, E., Kurnianta, A., Finn, C. \& Qian, M., 2007. Quantification of selected aroma-active compounds in strawberries by headspace solidphase microextraction gas chromatography and correlation with sensory descriptive analysis. J. Food Sci. 72, S487-S496.

Lafontaine, M., Schultz, H.R., Lopes, C., Bálo, B. \& Varadi, G., 2005. Leaf and fruit responses of Riesling grapevines to UV-radiation in the field. In: VII Int. Symp., California, USA. Grapevine Physiology and Biotechnology 689. pp. $125-132$.
Leffingwell, J.C. \& Leffingwell, D., 1991. GRAS flavor chemicals-detection thresholds. Perfumer Flavorist 16, 1-19.

Li, R. \& Jiang, Z.T., 2004. Chemical composition of the essential oil of Cuminum cyminum L. from China. Flavour Frag. J. 19, 311-313.

Marais, J., 1983. Terpenes in the aroma of grapes and wines: A review. S. Afr. J. Enol. Vitic. 4, 49-60.

Mateo, J. \& Jiménez, M., 2000. Monoterpenes in grape juice and wines. J. of Chromatogr. A 881, 557-567.

Mendes-Pinto, M.M., 2009. Carotenoid breakdown products the norisoprenoids - in wine aroma. Arch. Biochem. Biophys. 483, 236-245.

Mira de Orduña, R., 2010. Climate change associated effects on grape and wine quality and production. Food Res. Int. 43, 1844-1855.

Oliveira, J.M., Faria, M., Sá, F., Barros, F. \& Araújo, I.M., 2006. C -alcohols as varietal markers for assessment of wine origin. Anal. Chim. Acta 563, 300-309.

Osorio, C., Alarcon, M., Moreno, C., Bonilla, A., Barrios, J., Garzon, C. \& Duque, C., 2006. Characterization of odor-active volatiles in Champa (Campomanesia lineatifolia R. \& P.). J. Agric. Food Chem. 54, 509-516.

Pino, J.A. \& Mesa, J., 2006. Contribution of volatile compounds to mango (Mangifera indica L.) aroma. Flavour Frag. J. 21, 207-213.

Ristic, R., Downey, M.O., Iland, P.G., Bindon, K., Francis, I.L., Herderich, M. \& Robinson, S.P., 2007. Exclusion of sunlight from Shiraz grapes alters wine colour, tannin and sensory properties. Aust. J. Grape Wine Res. 13, $53-65$.

Schieberle, P. \& Grosch, W., 1988. Identification of potent flavor compounds formed in an aqueous lemon oil/citric acid emulsion. J. Agric. Food Chem. $36,797-800$

Schultz, H., 2000. Climate change and viticulture: A European perspective on climatology, carbon dioxide and UV-B effects. Aust. J. Grape Wine Res. $6,2-12$.

Selli, S., Canbas, A., Cabaroglu, T., Erten, H. \& Günata, Z., 2006. Aroma components of cv. Muscat of Bornova wines and influence of skin contact treatment. Food Chem. 94, 319-326.

Song J., Shellie C.K., Wang H. \& Qian C.M., 2012. Influence of deficit irrigation and kaolin particle film on grape composition and volatile compounds in Merlot grape (Vitis vinifera L.). Food Chem. 134, 841-850.

Wu, Y., Pan, Q., Qu, W. \& Duan, C., 2009. Comparison of volatile profiles of nine litchi (Litchi chinensis Sonn.) cultivars from Southern China. J. Agric. Food Chem. 57, 9676-9681.

Wu, Y., Zhu, B., Tu, C., Duan, C. \& Pan, Q., 2011. Generation of volatile compounds in litchi wine during winemaking and short-term bottle storage. J. Agric. Food Chem. 59, 4923-4931.

Yang, C., Wang, Y., Wu, B., Fang, J. \& Li, S., 2011. Volatile compounds evolution of three table grapes with different flavour during and after maturation. Food Chem. 128, 823-830.

Zhang, M., Xu, Q., Duan, C., Qu, W. \& Wu, Y., 2007. Comparative study of aromatic compounds in young red wines from Cabernet Sauvignon, Cabernet Franc, and Cabernet Gernischet varieties in China. J. Food Sci. 72, C248-C252. 